\title{
An experimental study of the interaction of two successive solitary waves in the swash: a strongly interacting case and a weakly interacting case
}

\author{
Nimish Pujara ${ }^{1 *}$ Philip L.-F. Liu ${ }^{1,2}$ and Harry H. Yeh ${ }^{3}$
}

July 22,2015

\author{
${ }^{1}$ School of Civil and Environmental Engineering, Cornell University, Ithaca, NY 14853 \\ ${ }^{2}$ Institute of Hydrological and Oceanic Sciences, National Central University, Jhongli, Taoyuan \\ 320, Taiwan \\ ${ }^{3}$ School of Civil \& Construction Engineering, Oregon State University, OR 97331
}

\begin{abstract}
The interaction of successive solitary waves in the swash zone have been studied using large-scale experiments with a simple bathymetry of a constant depth region, where the water depth was $1.72 \mathrm{~m}$, and a plane beach, whose slope was 1:12. Two wave cases were considered where two successive solitary waves of the same height were generated one after the other so that the wave crests were separated by the effective wavelength associated with a single solitary wave. In the weakly interacting case the swash period is smaller than the effective period associated with a single solitary wave, which leads to similar run-ups for the first and second wave, whereas in the strongly interacting case the swash period is larger than the effective period associated with a single solitary wave, which leads to a significant reduction in the run-up of the second wave. The degree to which there is an interaction between the swash uprush of the second wave and the downrush of the first wave is framed in terms of the solitary wave slope parameter, which predicts breaker type of the first wave. Previous data from literature are found to support this claim. Measurements of bed shear stress, bed pressure and the free-surface displacement at a location near the stillwater shoreline are used to describe how the dynamics of the boundary layer differ when the downrush of the first wave meets the incoming second wave in both cases.
\end{abstract}

Keywords: swash zone; solitary waves; bed shear stress; run-up.

\section{Introduction}

The swash zone is the subregion of the nearshore region that is periodically covered and uncovered by a flow of water due to wave action. It is recognized as an important dynamic zone for sediment

${ }^{*}$ Corresponding author. E-mail: np277@cornell.edu. Phone: +16073794272 
transport and beach morphological changes (see Masselink and Puleo (2006) and reviews by Elfrink and Baldock (2002); Brocchini and Baldock (2008); Bakhtyar et al. (2009)). The typical swash flow is characterized by shallow flow depths (Meyer and Taylor, 1972), bore- and bed-generated turbulence (Longo et al., 2002; Cowen et al., 2003; Sou et al., 2010), and cross-shore flow accelerations (Shen and Meyer, 1963; Baldock and Hughes, 2006).

To study an isolated swash event, laboratory studies frequently use a dam-break-generated bore to drive the swash on impermeable beds (e.g. Yeh et al., 1989; Barnes et al., 2009; O'Donoghue et al., 2010; Kikkert et al., 2012) and permeable beds (e.g. Kikkert et al., 2013; Othman et al., 2014; Postacchini et al., 2014), motivated by the close resemblance between a long wave that breaks in the surf zone before travelling as a fully-developed bore towards the shoreline and a dam-breakgenerated bore. Solitary waves have also been used to study isolated swash events, motivated by questions of tsunami run-up (reviews by Synolakis and Bernard, 2006; Madsen et al., 2008) and observations by Peregrine (1983) and others, who mentioned that long waves on a beach often resemble a train of solitary waves. Experimental studies of solitary waves approaching a beach include measurements of run-up (Li and Raichlen, 2002; Jensen et al., 2003; Pedersen et al., 2013), flow turbulence (Ting, 2006, 2008), and sediment transport (Kobayashi and Lawrence, 2004; Alsina et al., 2009; Sumer et al., 2011). A previous study by the authors (Pujara et al., 2015, henceforth referred to as PLY15) also examined the swash event driven by solitary waves on a plane beach to investigate the effects of wave breaking on the flow evolution, bed shear stress, and run-up in the swash.

The swash on natural beaches is often characterized by the arrival of multiple waves causing successive swash events that may interact with each other. These swash-swash interactions have been identified as an important feature for sediment transport (Puleo and Butt, 2006; Hughes and Moseley, 2007), run-up (Erikson et al., 2005; Lo et al., 2013) and the generation of low frequency waves (Watson et al., 1994; Brocchini and Baldock, 2008). Alsina et al. (2012) and Cáceres and Alsina (2012) have shown the importance of swash-swash interactions by using a wave-by-wave analysis of laboratory data - such interactions suspend significant amounts of sediment into the water column that can then be advected long distances in the cross-shore direction. On the other hand, Peregrine (1966), and more recently El et al. (2012), have shown that the evolution of an undular bore on a flat bottom and a gently sloping bottom leads to a system of multi-crested waves whose asymptotic form are solitary waves. Wiegel (1990) and Galvin (1990) showed a limited amount of field evidence for this process, known as soliton fission, in the case of the transformation of a long ocean swell over a reef. Thus, the interacting swash events of successive solitary waves arriving at a shoreline not only offers a convenient way to isolate swash-swash interactions, but may also be a common feature on natural beaches.

The aim of this study is to examine the swash of successive solitary waves using large-scale experiments with detailed measurements of the boundary layer, including direct measurements of bed shear stress using a shear plate sensor. Two specialized cases of two successive solitary waves, where wave crests are separated by the effective wave period of a single solitary wave, are generated to study two qualitatively different types of swash-swash interactions. The paper is organized as follows. The laboratory setup is described in section 2, including descriptions of the shear plate sensor and generation of successive solitary waves. Section 3 presents the results for the two wave cases. Section 4 discusses the results in the context of run-up of successive solitary waves and provides the conclusions. 


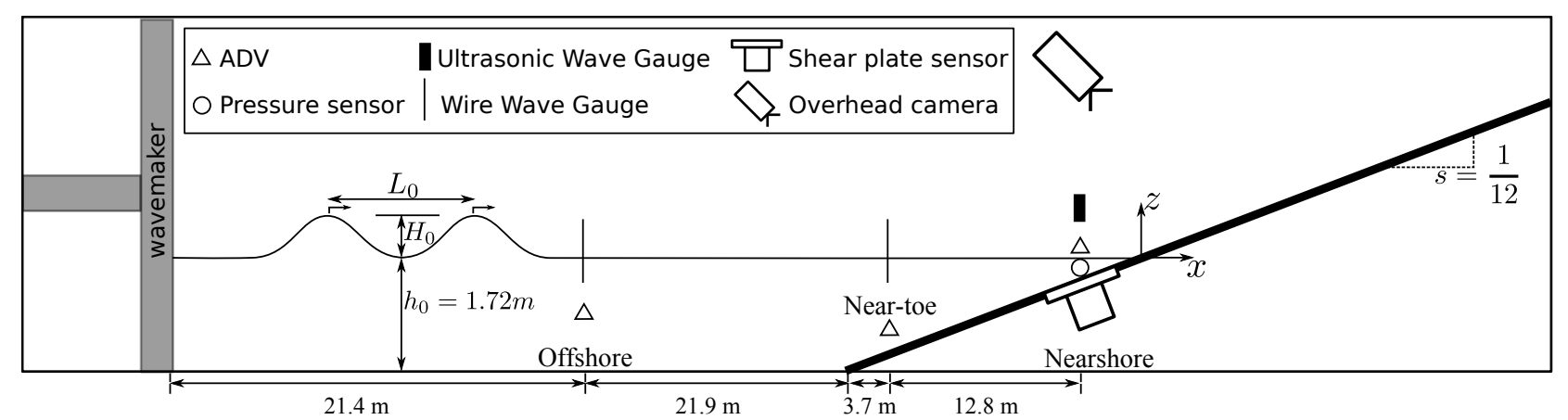

Figure 1: Schematic of experimental setup. The local stillwater depths at the near-toe location and nearshore location were $h=1.42 \mathrm{~m}$ and $h=0.1 \mathrm{~m}$, respectively.

\section{Laboratory Experiments}

\section{$2.1 \quad$ Experimental Setup}

The experiments were conducted in the Large Wave Flume (LWF) at the Hinsdale Wave Research Laboratory at Oregon State University. The LWF, which is a flume of length $104 \mathrm{~m}$, width $3.7 \mathrm{~m}$ and depth $4.6 \mathrm{~m}$, equipped with a piston-type wave-maker at one end of the flume and a plane beach of slope $s=1 / 12$ installed at the other end, is shown as a schematic in Figure 1 . In between the wave-maker and the toe of the beach, the flume bottom was horizontal and the water depth was kept constant at $h_{0}=1.72 \mathrm{~m}$. The incident waves were measured at the offshore location $21.4 \mathrm{~m}$ from the the wave-maker in its fully retracted position. The free-surface displacement was measured using a resistance-type wave gauge (custom designed for the LWF; estimated repeatability $<2 \mathrm{~mm}$ ), the water particle velocity was measured using an acoustic Doppler velocimeter (ADV; Nortek Vectrino with plus firmware, accuracy 1\%) installed at a depth of $1.1 \mathrm{~m}$ below the stillwater free-surface. Further measurements of the free-surface displacement and water particle velocity were also made at a location near the toe of the beach (the near-toe location shown in Figure 1) using a resistance-type wave gauge and an ADV installed at a depth of $0.8 \mathrm{~m}$ below the stillwater free-surface.

To allow the study of the interaction between the downrush of the first wave and the uprush of the second wave, additional measurements were made at the nearshore location shown in Figure 1, which was located at $x=-1.21 \mathrm{~m}$ and where the local stillwater depth was $h=0.10 \mathrm{~m}$. The local bed shear stress was measured using a shear plate sensor (more details below), the free-surface displacement was measured using an ultrasonic wave gauge (Senix TS-30S1 series; accuracy $1 \mathrm{~mm}$ ) mounted directly above the center of the shear plate sensor, the bed pressure was measured using a pressure transducer (Druck PDCR 830; accuracy $30 \mathrm{~Pa}$ ) installed so that its measurement face was flush with the bed, and the near-bed velocity was measured using a side-looking ADV (Nortek Vectrino with plus firmware) mounted with its measurement volume at a height of $2 \mathrm{~cm}$ above the bed. Note, the near-bed velocity measurements were not available when the water depth was less than approximately $7 \mathrm{~cm}$ because the ADV failed to make reliable measurements. A minimum threshold of $15 \mathrm{~dB}$ for the signal to noise ratio (SNR) was applied to the ADV measurements. All instruments at the nearshore location were co-located in the cross-shore direction, but the bed pressure sensor and the ADV were offset in the long-shore direction from the shear plate sensor. A photograph of the top view of the instrument setup is shown in Figure 2.

The shear plate sensor, shown as a schematic in Figure 3, was specifically designed to measure 


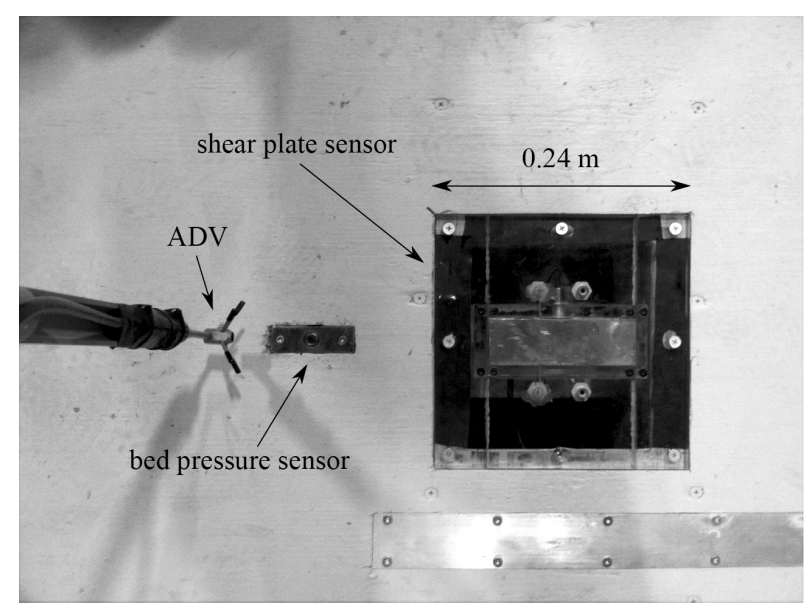

Figure 2: Photograph (top view) of instrument setup at nearshore location.

the local bed shear stress in the swash zone. A full description of the shear plate sensor is given in Pujara and Liu (2014), but a brief overview is provided here. The shear plate has dimensions of length $43 \mathrm{~mm}$ (cross-shore) and width $136 \mathrm{~mm}$ (long-shore) and thickness $0.8 \mathrm{~mm}$. The displacement of the shear plate due to the force of fluid friction on its surface area is measured by an eddy-current proximity probe; the probe uses the interaction between applied magnetic fields and induced eddy-currents to gauge the distance from the probe face to the target plate (labelled in Figure 3). The displacement of the shear plate is resisted by cylindrical links of known stiffness attached to the shear plate on its underside. The links maintain a right angle with the shear plate and the base plate, acting as a clamped guided cantilever system. A small gap of $1 \mathrm{~mm}$ surrounds the perimeter of the shear plate to allow for deflections. The shear plate sensor has a range of $\pm 200 \mathrm{~Pa}$ and an accuracy of $\pm 1 \%$, making it suitable for measuring the large bed shear stresses in the swash zone. In the presence of streamwise pressure gradients, there exists a secondary force on the shear plate, but this is corrected for using the treatment provided in Pujara and Liu (2014). The principal advantage of the shear plate sensor is its ability to make direct measurements of bed shear stress throughout the swash cycle without assumptions of the structure of the boundary layer flow.

Apart from the measurements in the swash, the shoreline motion was also tracked using two overhead cameras (Panasonic AW-HE60), which yielded images with a resolution of $1 \mathrm{~cm} / \mathrm{pixel}$ after processed to remove perspective. A tracking algorithm, which looked for large optical gradients was used to track the shoreline during the uprush phase. It was not possible, however, to track the shoreline position during the downrush phase since it did not create an indentifiable optical signature.

\subsection{Successive Solitary Waves}

In water of constant depth, $h_{0}$, the leading order solution to the solitary wave free-surface displacement is the well-known Boussinesq profile (Boussinesq, 1872) given by

$$
\eta(x, t)=H_{0} \operatorname{sech}^{2}\left[K_{0}\left(x-c_{0} t\right)\right]
$$

where $K_{0}=\sqrt{\left(3 H_{0}\right) /\left(4 h_{0}^{3}\right)}$ and the wave celerity $c_{0}=\sqrt{g\left(h_{0}+H_{0}\right)}$. The dimensionless wave height is given by $\epsilon_{0}=H_{0} / h_{0}$. Following Madsen et al. (2008), values for the effective wavelength and effective period can be defined by, 


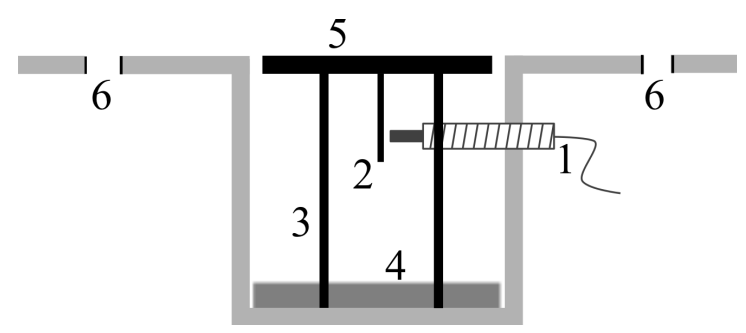

Figure 3: Schematic of shear plate sensor. 1: eddy-current proximity probe; 2: target plate; 3: cylindrical links; 4: base plate; 5: shear plate; 6: pressure tappings. Adapted from Pujara and Liu (2014).

\begin{tabular}{|c|c|c|c|c|c|c|c|c|c|}
\hline Wave & $\begin{array}{l}H_{0} \\
(\mathrm{~m})\end{array}$ & $\epsilon_{0}$ & $\begin{array}{c}L_{0} \\
(\mathrm{~m})\end{array}$ & $\begin{array}{l}T_{0} \\
(\mathrm{~s})\end{array}$ & $T_{\mathrm{sep}} / T_{0}$ & $S_{0}$ & $\begin{array}{c}\text { Breaker } \\
\text { type }\end{array}$ & $\begin{array}{c}R \\
(\mathrm{~m})\end{array}$ & $\begin{array}{c}R_{d} \\
(\mathrm{~m})\end{array}$ \\
\hline SW1A & .169 & .098 & 40.3 & 9.3 & \multirow{2}{*}{0.96} & 0.41 & NB & 0.60 & 0.17 \\
\hline SW1B & 0.170 & 0.098 & 40.0 & 9.3 & & $\mathrm{~N} / \mathrm{A}$ & $\mathrm{SU}$ & 0.48 & 0.18 \\
\hline PLY15-W3 & 0.173 & 0.100 & 39.6 & 9.2 & $\mathrm{~N} / \mathrm{A}$ & 0.40 & NB & 0.61 & 0.18 \\
\hline SW2A & 0.334 & 0.193 & 28.6 & 6.3 & \multirow{2}{*}{0.93} & 0.29 & $\mathrm{PL}$ & 0.96 & $\mathrm{~N} / \mathrm{A}$ \\
\hline SW2B & 0.331 & 0.191 & 28.7 & 6.4 & & $\mathrm{~N} / \mathrm{A}$ & $\mathrm{SU}$ & 0.45 & 0.25 \\
\hline PLY15-W7 & 0.345 & 0.199 & 28.1 & 6.2 & $\mathrm{~N} / \mathrm{A}$ & 0.28 & PL & 0.96 & 0.20 \\
\hline
\end{tabular}

Table 1: Properties of solitary waves generated. PLY15-W3 and PLY15-W7 refer to wave cases in PLY15. NB is a non-breaking wave, $\mathrm{SU}$ is a surging breaker, PL is a plunging breaker. $T_{\text {sep }}$ is the separation time between successive wave crests at the offshore location. The run-up, $R$, and the run-down, $R_{d}$, are measured vertically from the stillwater shoreline.

$$
L_{0}=\frac{2 \pi}{K_{0}}, T_{0}=\frac{2 \pi}{K_{0} c_{0}},
$$

respectively. Grilli et al. (1997) introduced a solitary wave slope parameter that predicts the breaker type of a solitary wave when it climbs a plane sloping beach. The slope parameter is a ratio between the solitary wave effective wavelength and the horizontal distance from the toe of the beach to the shoreline, $h_{0} / s$, where $s$ is the beach slope. Grilli et al. (1997) chose a different effective wavelength than Eq. (2.2); they chose the effective wavelength to be the horizontal distance between the points with maximum slope on the solitary wave profile described by Eq. (2.1). Following this procedure, Grilli et al. (1997) found the solitary wave slope parameter, and the corresponding breaker types, to be

$$
S_{0}=1.521 \frac{s}{\sqrt{H_{0} / h_{0}}} ; \text { breaker type }= \begin{cases}\text { No breaking, } & \text { if } S_{0}>0.37 \\ \text { Surging, } & \text { if } 0.3<S_{0}<0.37 \\ \text { Plunging, } & \text { if } 0.025<S_{0}<0.3 \\ \text { Spilling, } & \text { if } S_{0}<0.025\end{cases}
$$

Two wave cases, referred to as SW1 and SW2, were studied. Each wave case consisted of two successive solitary waves and the letters A and B are used to refer to the first and the second wave, respectively. An additional run of SW2 was conducted and the data from the repeated runs are plotted together to demonstrate the high degree of repeatability in the experiments. Table 1 gives the properties of the waves in the constant depth region and results such as values of the run-up 


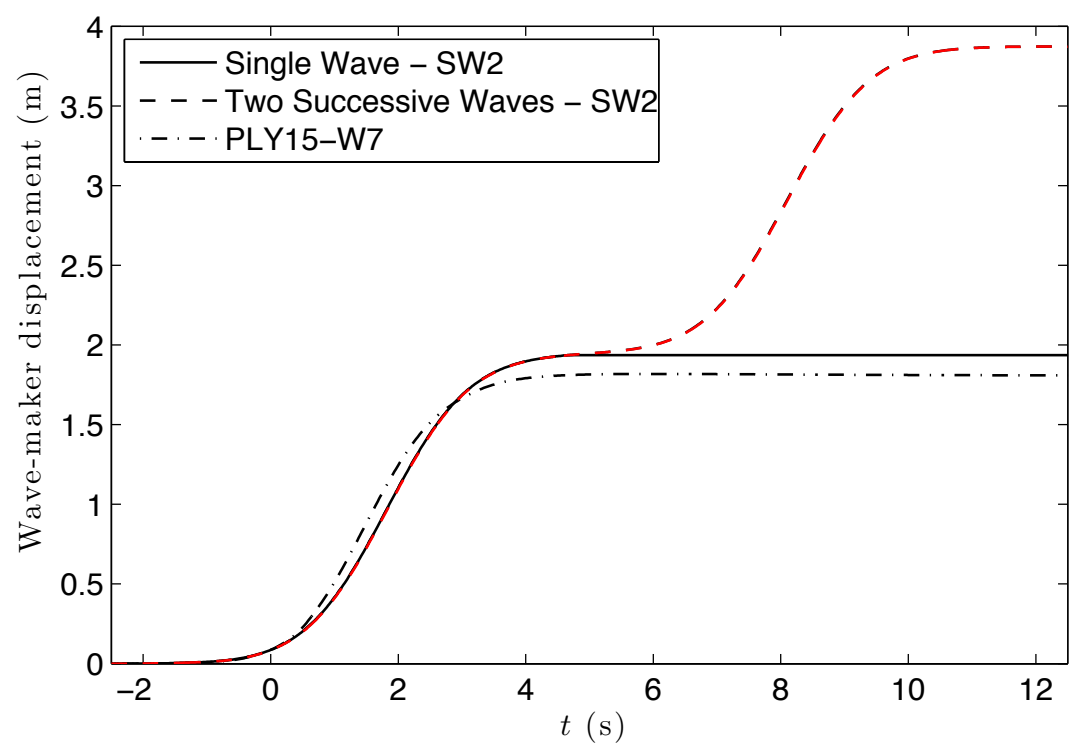

Figure 4: Wave-maker trajectories for SW2 and hypothetical wave-maker trajectories for single solitary waves in SW2. Data from the repeated run is plotted in red and shows a very good match to the first run. Wave-maker trajectory for W7 from PLY15 is also shown.

and run-down. The run-up, $R$, is defined as the maximum vertical elevation of the water above the stillwater shoreline in the uprush phase and the run-down, $R_{d}$, is defined as the vertical distance below the stillwater shoreline where a hydraulic jump occurs in the downrush phase. The values for the effective wavelength, $L_{0}$, and the effective period, $T_{0}$, given in Table 1 are calculated according to Eq. (2.2) using measurements of the wave height at the offshore location. The trajectory of the wave-maker to produce a single solitary wave was calculated using the method of Goring (1978) and successive solitary waves were generated by creating a composite wave-maker trajectory where the trajectory for a single solitary wave was performed twice successively (cf. Lo et al. (2013)). Figure 4 shows the wave-maker trajectory for two successive solitary waves compared to the wavemaker trajectory for single solitary wave. The successive waves were thus generated with identical wave-maker motion, but a slow evolution led to slightly different wave heights. This slow evolution of successive waves had negligible influence - even the shortest wave, SW2A, travelled a horizontal distance of only approximately twice its own wavelength before reaching the toe of the sloping beach - and the swash was essentially driven by two successive identical solitary waves separated by the wavelength of a single solitary wave (Table 1 ).

At the offshore location, the free-surface displacement of the waveforms are compared to the Boussinesq solution, Eq. (2.1), for SW2 in Figure 5. Wave A matches the Boussinesq solution very well, whereas the trailing edge of wave B shows some discrepancy. The data for SW1 at the offshore location show a similar agreement with the Boussinesq solution.

The single solitary wave cases W3 and W7 from PLY15 correspond very closely to the solitary waves in SW1 and SW2, respectively. This allows data from successive waves to be compared to a single solitary wave (Table 1 ). 


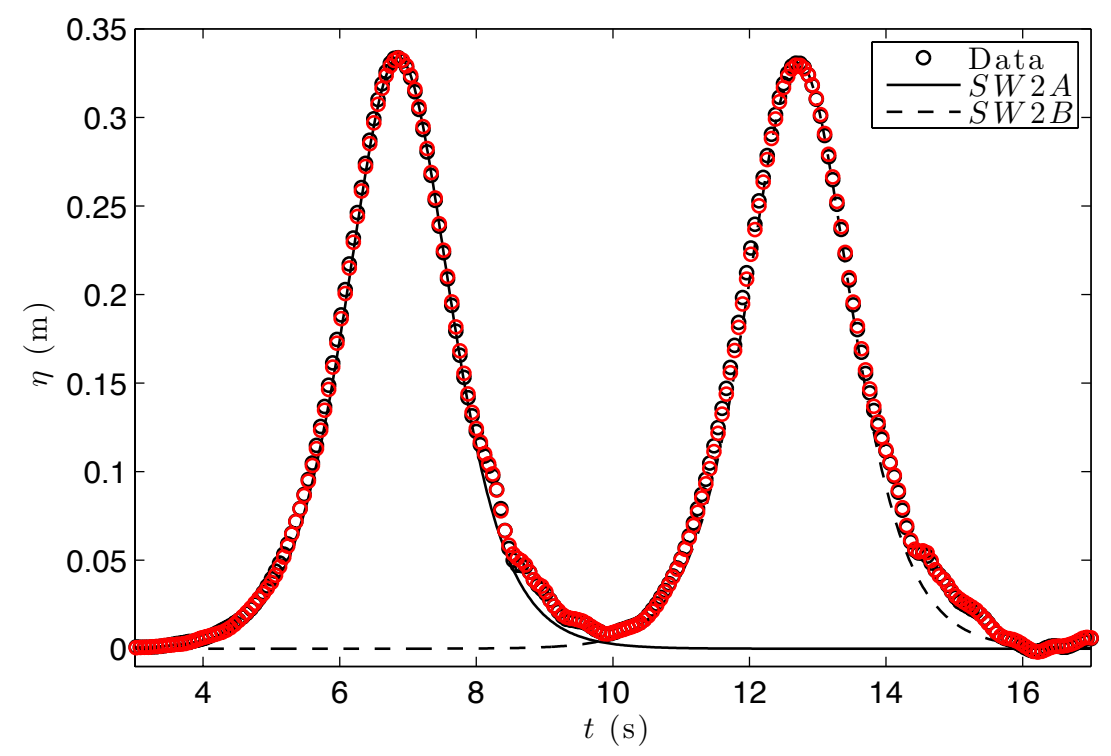

Figure 5: Free-surface displacement for SW2 at the offshore location. Solid line: Boussinesq solution, Eq. (2.1), for SW2A; Dashed line: Boussinesq solution, Eq. (2.1), for SW2B. Data from the repeated run is plotted in red and shows a very good match to the first run.

\section{Results}

\subsection{SW2: strongly interacting case}

The key features in the swash of SW2 are depicted in Figure 6, including the wave collapse location, where the wave overturning jet reconnected with land/water in front of it and the waveform was first seen to disintegrate into water with air entrained.

The swash zone flow of the first wave follows the swash solution given in Peregrine and Williams (2001) (as shown by PLY15 for their W7), until the arrival of the second wave, SW2B. Figure 7 plots the position of the leading edge of the swash for SW2. The leading edge of the swash is referred to as the swash tip herein and it's position in the $x$-coordinate is denoted as $x_{s}$. For the swash of the first wave, the swash tip coincides with the shoreline and can be identified from the

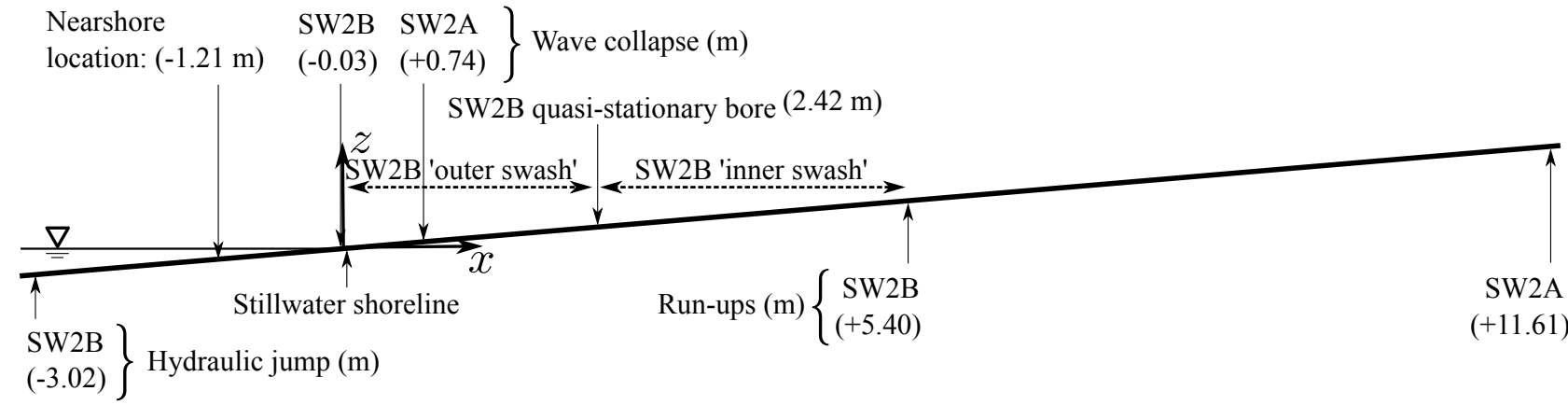

Figure 6: A diagram, to scale, of the swash zone for SW2. Numbers in brackets show the value of $x$, the distance along the beach measured from the stillwater shoreline. The wave collapse locations refer to where the waveform was first seen to collapse. Dashed arrows indicate the extents of 'outer swash' and 'inner swash' for SW2B. 


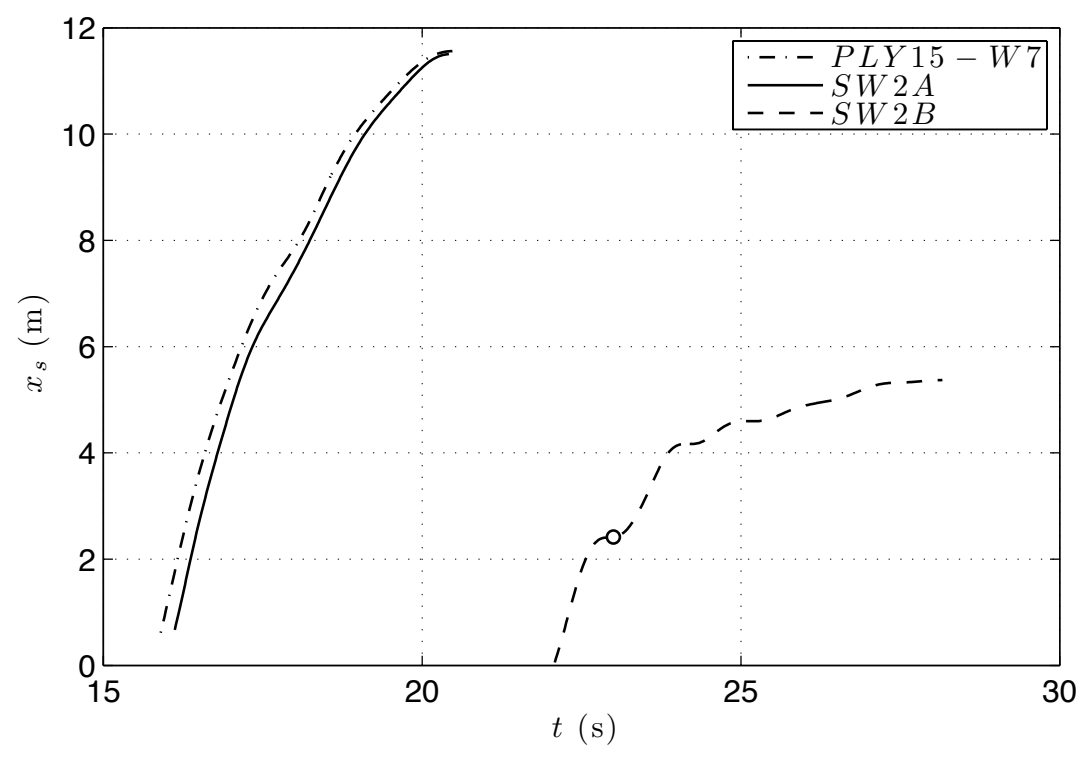

Figure 7: Shoreline (or swash tip) motion for SW2. o: the swash tip of SW2B is temporarily halted in space at $x_{s} \approx 2.42 \mathrm{~m}$ and $t \approx 23 \mathrm{~s}$.

overhead camera images, whereas for the second wave, the actual shoreline was difficult to identify due to the wet surface and the extremely thin-layered flow. The swash tip for SW2A travels in a very similar trajectory to the swash tip for PLY15-W7, leading to a very similar run-up (Table 1), but the swash tip for SW2B follows a very different trajectory. The wavefront of SW2B collapses at a location further offshore than the collapse of SW2A (Figure 6). As the swash tip for SW2B climbs the slope against the downrush of SW2A, there is a strong interaction between the two flows and the swash tip of SW2B is held in space temporarily by the downrush of SW2A and a quasi-stationary bore occurs at $x \approx 2.42 \mathrm{~m}$ and $t \approx 23 \mathrm{~s}$. The swash tip of SW2B then climbs further up the beach to reach a run-up that is approximately $45 \%$ of the run-up of SW2A - a significant reduction due to the strong interaction between the second wave uprush and the first wave downrush. (Run-up in this study is always with reference to the stillwater shoreline.) The flow velocity at the location of the quasi-stationary bore at $x \approx 2.42 \mathrm{~m}$ must be negative after the bore collapses at $t \approx 23 \mathrm{~s}$, making the interaction a 'strong wave-downrush interaction' (Hughes and Moseley, 2007; Cáceres and Alsina, 2012; Alsina et al., 2012). The swash flow of SW2B in the region $2.42<x<5.40 \mathrm{~m}$ is in the 'inner swash' according to the Hughes and Moseley (2007) classification since that region does not experience interacting swash events (see Figure 6), but it is clear from the trajectory of the swash tip that the swash flow in this inner swash is weakened by the interaction further offshore. The hydraulic jump of the downrush of the combined swash flow occurs offshore of the stillwater shoreline, as shown in Figure 6.

Figure 8 plots the free-surface displacement and the horizontal velocity at the near-toe location (see Figure 1). There are two incident waves, with positive free-surface displacement and positive (onshore-directed) velocity, but the signal due to the reflection of the waves (negative, offshoredirected velocity) shows a merged reflected wave with a peak in free-surface displacement at $t \approx 31$ s. This feature is further evidence of the strong interaction between the swash events, since the reflected wave signal does not show two distinct waves (cf. Lo et al., 2013).

Figure 9 plots the free-surface displacement, $\eta$, the bed pressure, $p_{b}$, the near-bed velocity, $u$, and the bed shear stress, $\tau_{b}$, at the nearshore location for SW2. At $t_{1}=16.3 \mathrm{~s}$, there exist 


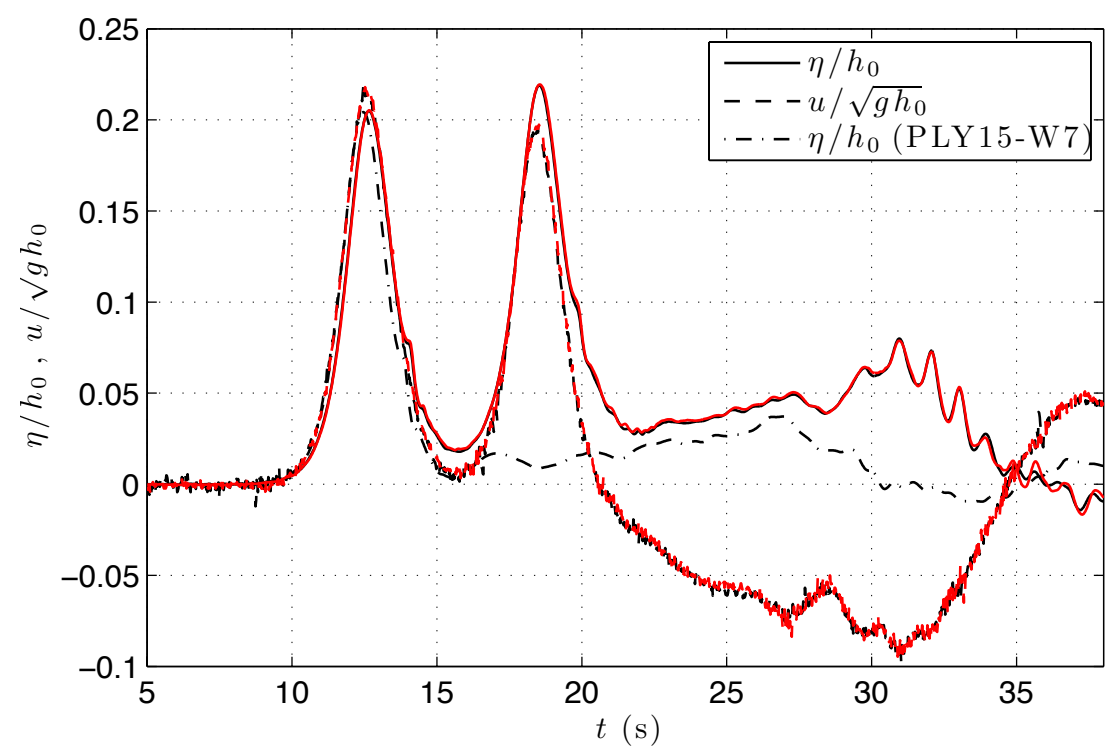

Figure 8: Free-surface displacement, $\eta$, and horizontal velocity, $u$, at near-toe location, $h=1.42$ $\mathrm{m}$, for SW2. The hump at $t \approx 31 \mathrm{~s}$ corresponds to the reflected wave due to the combined swash events of SW2. Data from the repeated run is plotted in red and shows a very good match to the first run.

fluctuations in bed pressure and bed shear stress that are likely due to the collapse of SW2A that causes the beach to vibrate. Time $t_{2}=19 \mathrm{~s}$ is the start of the downrush at the nearshore location as the velocity and bed shear stress change sign. The wavefront of SW2B arrives at $t_{3}=22 \mathrm{~s}$, but it is insufficiently steep to break - SW2B collapses further onshore as shown in Figure 6 - and so there is a smooth transition from offshore-directed flow to onshore-directed flow that is further discussed below. The height of the SW2B wave crest is larger than the wave crest of SW2A, but the peak near-bed velocity is lower, due to the raised water elevation in the downrush of SW2A. Consequently, the peak bed shear stress is lower under the wave crest of SW2B compared to the wave crest of SW2A at this location. The strong interaction between SW2B and the downrush of SW2A occurs onshore of the nearshore location. At the nearshore location, the downrush results in a large, negative bed shear stress due to accelerating flow and decreasing water depth $\left(t_{4}=30\right.$ $\mathrm{s})$.

Figure 10 plots the same data from the nearshore location, but truncated in time around $t_{3}=$ $22.0 \mathrm{~s}$ to focus on the flow reversal. Vertical accelerations are important in the steep wavefront of SW2B as seen by the difference between the bed pressure and the free-surface elevation. Attention is drawn to the instances marked (3a) and (3b) in Figure 10, for which sketches of the velocity profiles and flow patterns are shown in Figure 11. At instance (3a), the vertical acceleration must be positive (upward-directed) to cause an increase in the free-surface steepness and this is accompanied by bed pressure that is higher than hydrostatic, whereas at instance (3b), the vertical acceleration must be negative (downward-directed) to cause a decrease in the free-surface steepness and this is accompanied by bed pressure that is lower than hydrostatic. The bed shear stress goes to zero at instance (3a) while the near-bed velocity is still offshore-directed and before the freesurface begins to rise because of the 'extra' horizontal pressure gradient due to the non-hydrostatic pressure distribution in the wavefront of SW2B (e.g. Peregrine, 1966). Thus, the bed shear stress leads the near-bed velocity and the free-surface elevation in phase at instance (3a). At instance (3b), the near-bed velocity and the bed shear stress are both positive and both become lower in 

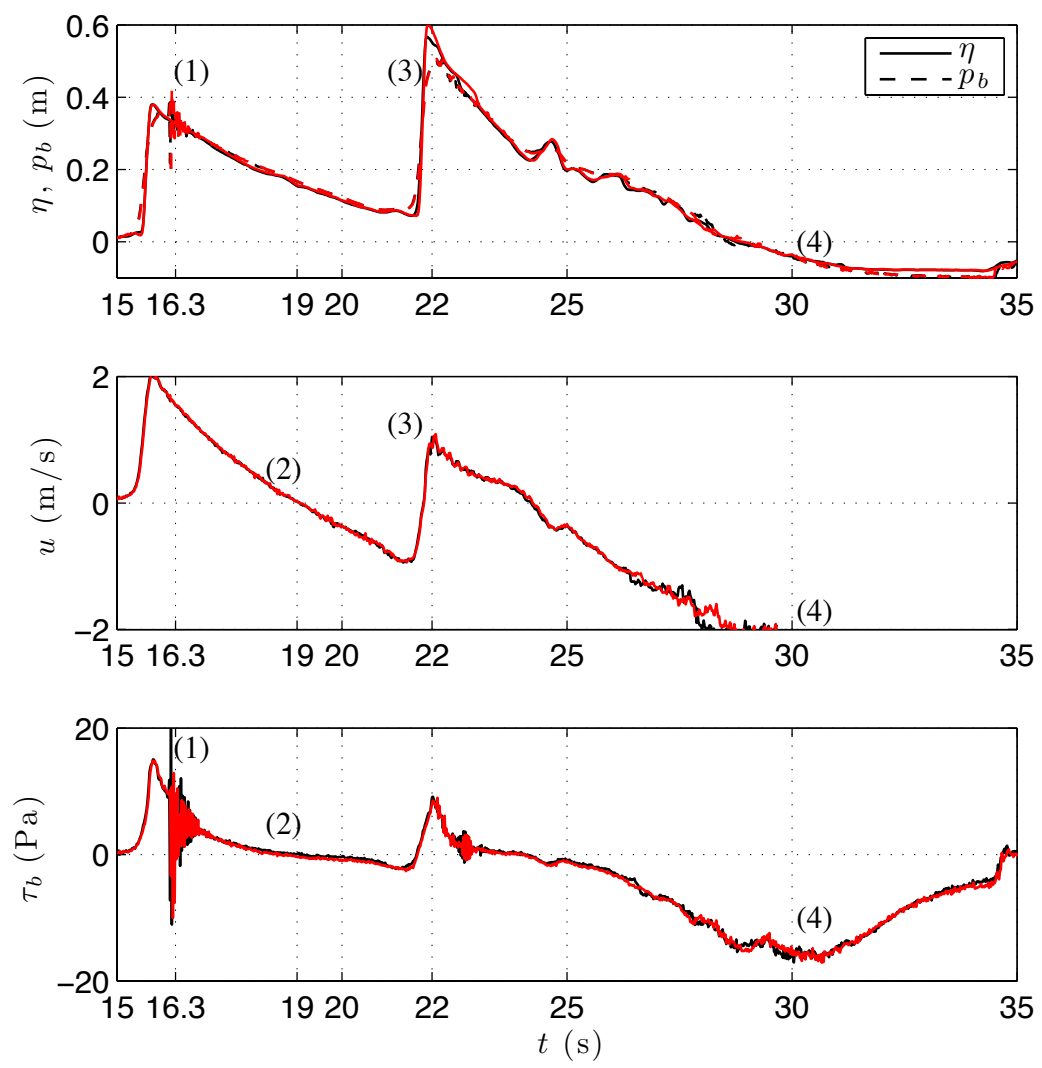

Figure 9: Data at the nearshore location $(h=0.10 \mathrm{~m})$ for SW2. Top panel: Free-surface displacement, $\eta$, and bed pressure, $p_{b}$; Middle panel: Near-bed velocity, $u$; Bottom panel: Bed shear stress, $\tau_{b}$. Data from the repeated run is plotted in red and shows a very good match to the first run. 

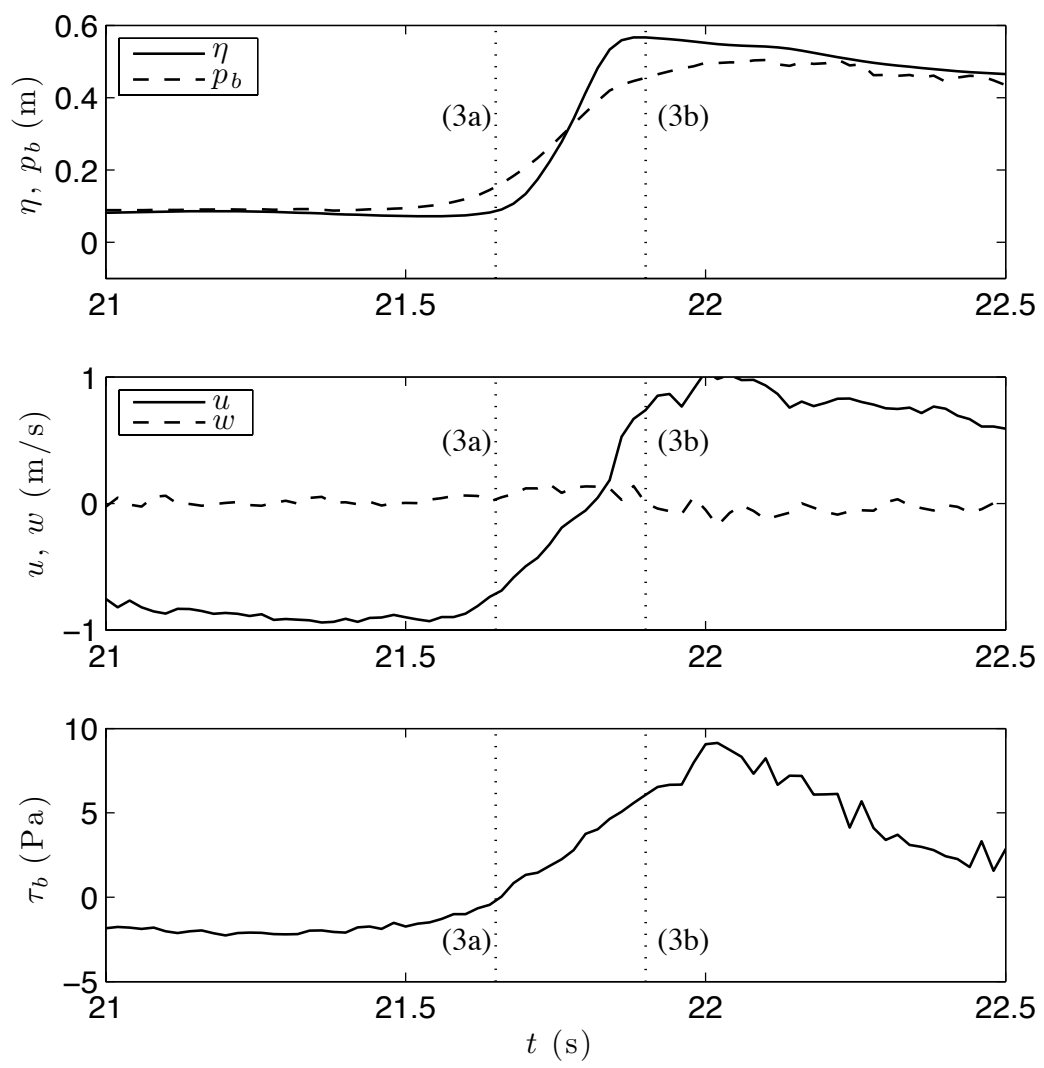

Figure 10: Data at the nearshore location $(h=0.10 \mathrm{~m})$ for SW2. Top panel: Free-surface displacement, $\eta$, and bed pressure, $p_{b}$; Middle panel: Near-bed velocity, $u, w$; Bottom panel: Bed shear stress, $\tau_{b}$.

magnitude than behind the wave crest.

\subsection{SW1: weakly interacting case}

The key features of the swash of SW1 are depicted in Figure 12. The swash event of the nonbreaking wave SW1A is almost complete, i.e., the swash tip for SW1A reaches its run-up and the downrush of SW1A develops into a hydraulic jump, before the wavefront of SW1B arrives. The downrush of SW1A induces breaking in the wavefront of SW1B, which collapses at a location onshore of the hydraulic jump caused by the downrush of SW1A. The broken bore of SW2B continues to travel against the downrush of SW1A and creates its own uprush that reaches a runup $20 \%$ lower than that of SW1A. If the run-up of SW1B is measured from the location of the hydraulic jump of SW1A, i.e., the run-down limit of the previous wave (as suggested by Baldock et al., 2008), the run-up of SW1B becomes $R_{B}=0.65 \mathrm{~m}$, even high, but close to the run-up of SW1A $R_{A}=0.6 \mathrm{~m}$. The interaction between the swash uprush of SW1B and the downrush of SW1A is a 'weak wave-downrush interaction' (Hughes and Moseley, 2007; Cáceres and Alsina, 2012; Alsina et al., 2012) since the velocity continues due to be onshore-directed as the uprush of SW1B climbs to reach a run-up similar to that of SW1A. The weak interaction is evidenced in the motion of the swash tips of SW1A and SW1B, plotted in Figure 13, which follow similar trajectories though the swash tip for SW1B forms offshore of the stillwater shoreline.

Figure 14 shows the free-surface displacement and horizontal velocity from the near-toe location. 

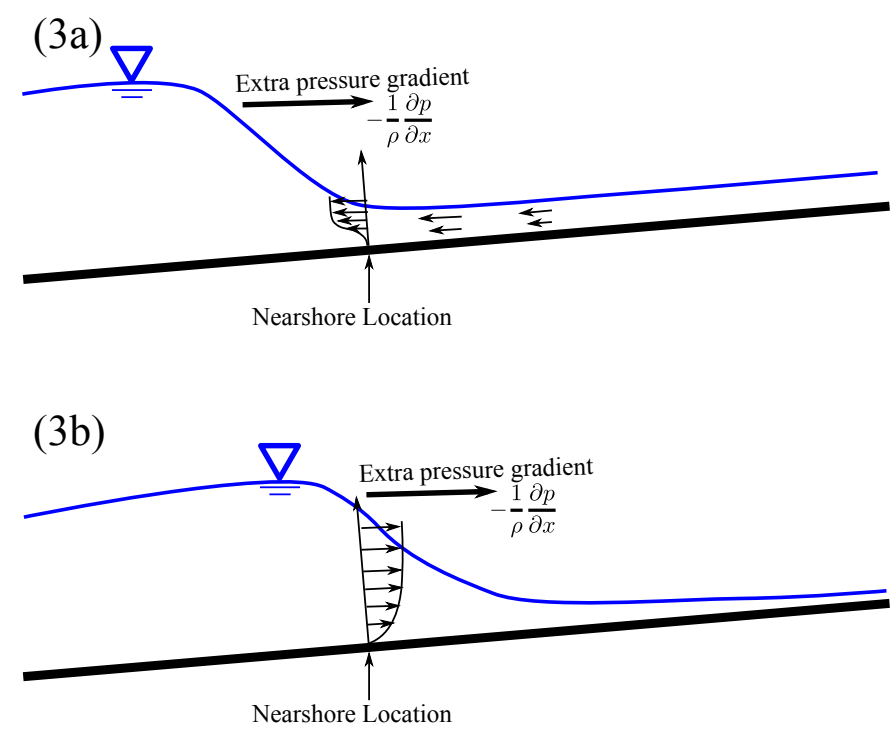

Figure 11: Sketch of flow patters and velocity profile corresponding to points (3a) and (3b) in Figure 10.

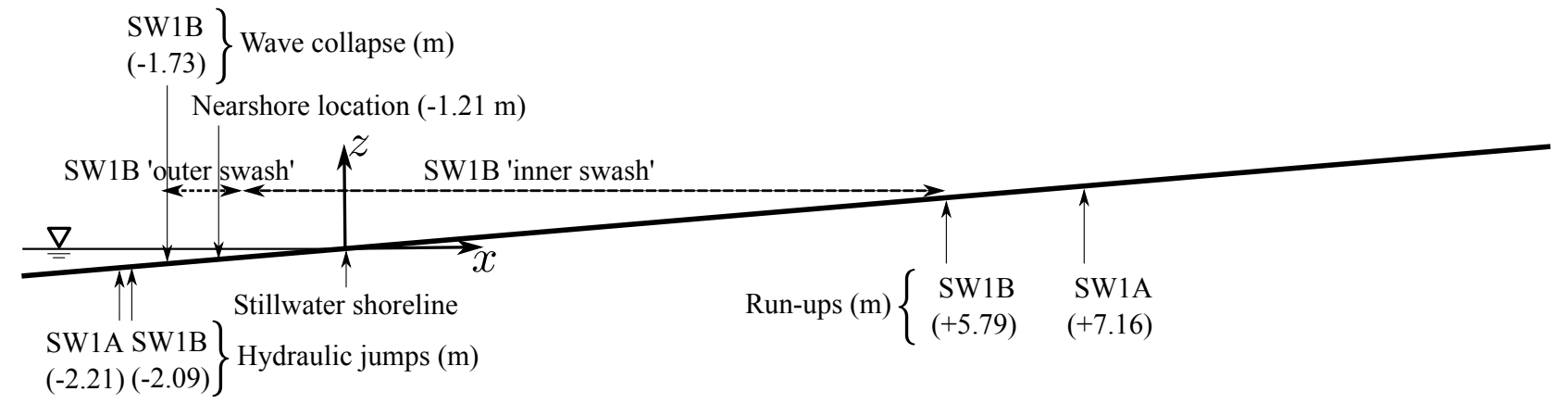

Figure 12: A diagram, to scale, of the swash zone for SW1. Numbers in brackets show the value of $x$, the distance along the beach measured from the stillwater shoreline. The wave collapse locations refer to where the waveform was first seen to collapse. Dashed arrows indicate the extents of 'outer swash' and 'inner swash' for SW1B. 


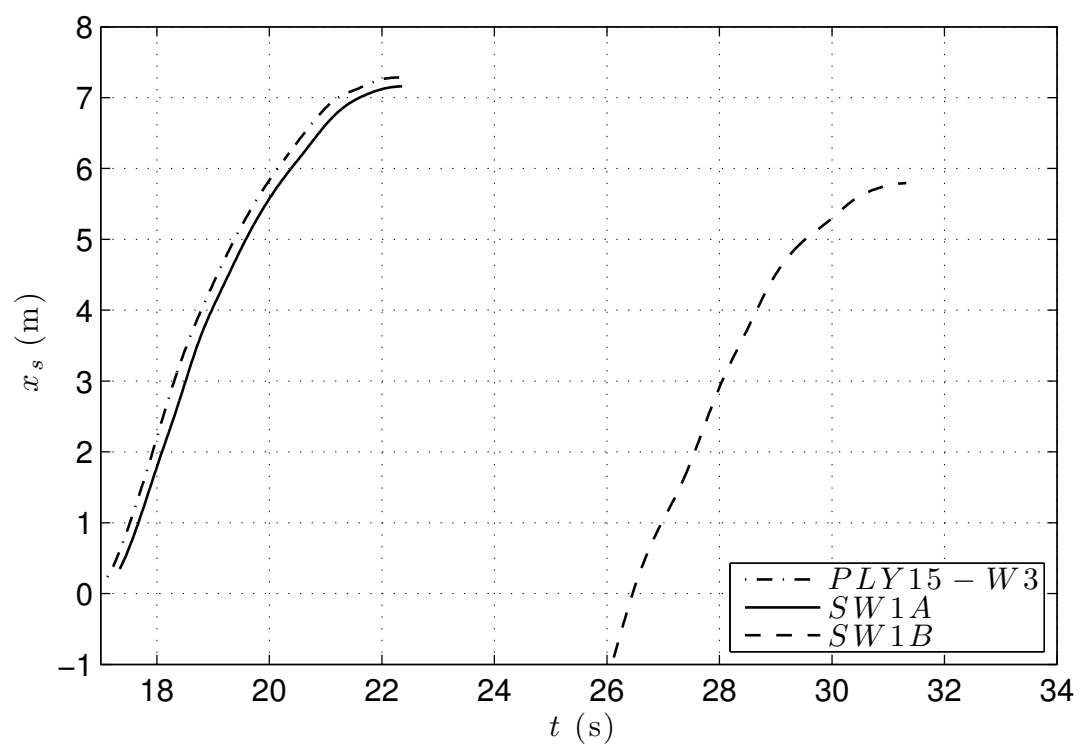

Figure 13: Shoreline (or swash tip) motion for SW1.

It can be seen that there are two distinct reflected waves from the beach that must correspond to reflections of SW1A and SW1B, respectively. Two separate reflected waveforms further indicates that the interaction of the successive swash events is weak.

Figure 15 plots the free-surface displacement, $\eta$, the bed pressure, $p_{b}$, the near-bed velocity, $u$, and the bed shear stress, $\tau_{b}$, at the nearshore location for SW1. The wavefront of SW1A, which has mild steepness consistent with its classification as a non-breaking wave, is marked at $t_{4}=16 \mathrm{~s}$. After the passage of the incident wave, the downrush develops starting at $t_{5}=20 \mathrm{~s}$ and continues until $t_{6}=26.2 \mathrm{~s}$ when the swash tip of of SW1B arrives. The top panel of Figure 15 shows that the shoreline during downrush has almost reached the nearshore location at $t_{6}=26.2 \mathrm{~s}$ as the total water depth $\eta+h \approx 0$ (stillwater depth at the nearshore location is $h=0.1 \mathrm{~m}$ ). Thus, almost the entire swash of SW1B is in the 'inner swash' (Hughes and Moseley, 2007) since it is free from interactions of the previous swash event (see Figure 12). However, there still exists a large negative velocity associated with the downrush flow at $t_{6}=26.2 \mathrm{~s}$ and the opposing flow fields create a flow separation at the bed, which is further discussed below. In contrast to the data for SW2, the maximum elevation of the free-surface for SW1B is about the same as SW1A but the peak near-bed velocity is larger for SW1B than SW1A. These differences between SW2 and SW1 are due to the fact that SW1B forms a broken bore by the time it arrives at the nearshore location, whereas SW2B collapses onshore of the nearshore location. The breaking process causes a decrease in wave height and an increase in the water particle velocity.

Figure 16 plots the same data from the nearshore location, but truncated in time around $t_{6}=26.2 \mathrm{~s}$ to focus on the flow separation event. Attention is drawn to the instances marked (6a) and (6b). Prior to instance (6a), there is a large negative bed shear stress in the downrush of SW1A as the water depth is slowly decreasing. There is also a downward tumbling flow in the bore front as seen from the negative vertical velocity, $w$. The temporal vertical flow acceleration, $\partial w / \partial t$, is negative and the bed pressure has a lower magnitude than the free-surface elevation, both of which show that this flow is also accompanied by negative (downward-directed) vertical acceleration of fluid particles and non-hydrostatic pressure distribution. At the instance (6a), the pressure suddenly increases, but the bed shear stress still remains negative indicating that the flow 


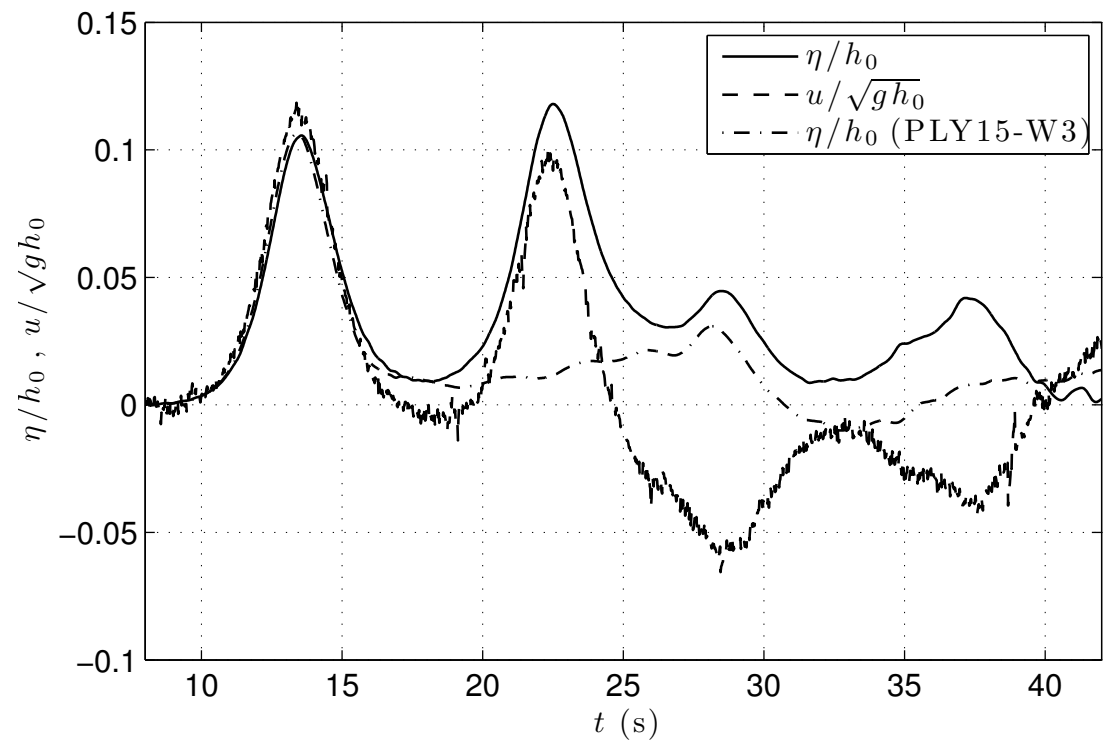

Figure 14: Free-surface displacement, $\eta$, and horizontal velocity, $u$, at near-toe location, $h=1.42$ $\mathrm{m}$, for SW1. The humps at $t \approx 28.5 \mathrm{~s}$ and $t \approx 37.5 \mathrm{~s}$ correspond to reflected waves due to SW1A and SW1B, respectively.
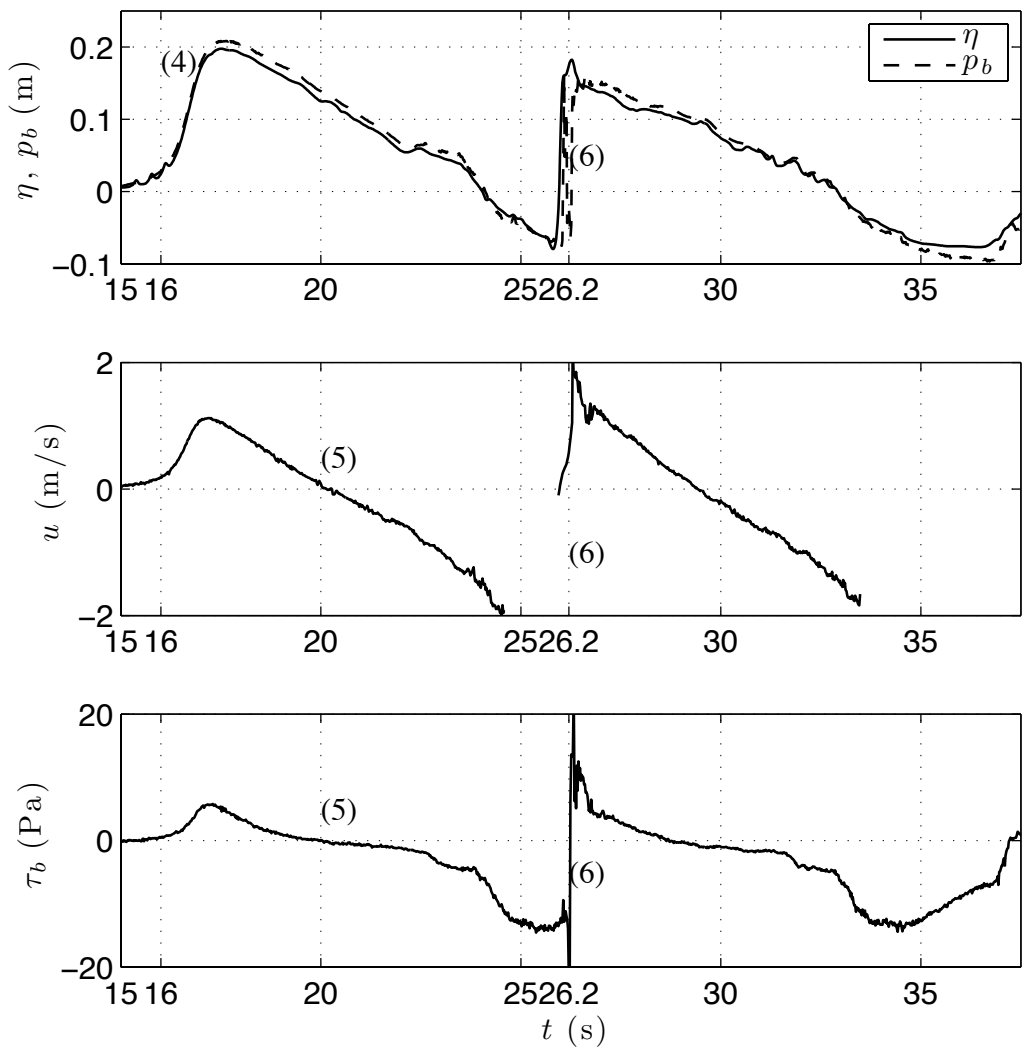

Figure 15: Data at the nearshore location $(h=0.10 \mathrm{~m})$ for SW1. Top panel: Free-surface displacement, $\eta$, and bed pressure, $p_{b}$; Middle panel: Near-bed velocity, $u$; Bottom panel: Bed shear stress, $\tau_{b}$. 
nearest to the bed is still offshore-directed due to the downrush of SW1A, but the near-bed velocity is positive. Thus, the flow must be flowing in different directions in the water column. A sketch of the the velocity profiles and flow patterns is given in Figure 17. Immediately after instance (6a), the bed shear stress shows a sudden decrease to a larger negative value, which may be due to boundary layer thinning caused by uprush flow of the bore. Note, that the location of pressure transducer is not exactly the same as that of the shear plate (see Figure 2), and the bore front is not precisely two-dimensional (the surface roller of a bore has a three-dimensional structure, Yeh and Mok, 1990). Therefore, we anticipate the data shown in Figure 16 to contain small discrepancies in timing between instruments. At instance $(6 \mathrm{~b})$, the bed shear stress transitions from negative to positive and this transition is sudden, suggesting the occurrence of bursting. The negative spike in the bed pressure at instance (6b) indicates that the flow separation is accompanied by positive (upward-directed) vertical acceleration of fluid particles and non-hydrostatic pressure distribution. The near-bed velocity in the horizontal direction remains onshore-directed. The velocity profile and flow patterns for instance $(6 \mathrm{~b})$ are also sketched in Figure 17. Immediately behind the bore front, the magnitude of shear stress becomes much smaller than that of the downrush. As the bore propagates onshore, the flow separation point must move onshore until the bore of SW1B climbs far enough to reach dry land. The dominant bed-load sediment transport in the downrush and the dominant suspended-load sediment transport in the swash zone are discussed by Jackson et al. (2004); Pritchard (2009); Cáceres and Alsina (2012) and others. Our measurements show the quantitative evidence for the sediment-transport mechanism when there is an interaction of the downrush of the previous wave with the broken bore of the following wave: the strong bed shear stress in the downrush of the previous wave mobilizes sediment as bed-load and the burstlike vertical fluid accelerations associated with the flow separation point picks up the bed-load sediment into the bore. Sou and Yeh (2011) also discussed this mechanism in their study of the swash of plunging regular waves using particle image velocimetry (PIV) measurements, but here it is shown for larger-scale experiments and using the direct measurements of bed shear stress and bed pressure.

\section{Further discussion}

It would be useful to link the interaction of waves in the swash to the properties of the incident waves and the beach slope. We attempt to establish this link for the swash of two successive solitary waves with wave crests separated by approximately one wavelength using the breaker type of a single solitary wave, i.e., the solitary wave slope parameter, $S_{0}$. Figure 18, reproduced from PLY15, plots the swash period, $T_{s}$, defined as the time from wave collapse in uprush to the occurrence of the hydraulic jump during downrush, normalized by the incident wave period, $T_{0}$, as a function of $S_{0}$. As the solitary wave slope parameter decreases, i.e., moving from non-breaking waves to surging breakers to plunging breakers, the time period of the swash relative to the incident wave period increases. For non-breaking waves $\left(S_{0}>0.37\right), T_{s} / T_{0}<1$, but for the plunging breakers in PLY15 $\left(0.025<S_{0}<0.3\right), T_{s} / T_{0}>1.2$. For SW1 $\left(S_{0}=0.41, T_{s} / T_{0} \approx 0.85\right)$, the interaction between the wavefront of wave $\mathrm{B}$ with the swash of wave A occurs when the swash event of wave A is almost complete, whereas for SW2 $\left(S_{0}=0.29, T_{s} / T_{0} \approx 1.1\right)$, the interaction between wavefront of wave B and the swash of wave A occurs when there is a strong downrush flow.

Figure 19 plots the run-up of wave B normalized by the run-up of wave $\mathrm{A}, R_{B} / R_{A}$, as a function of the solitary wave slope parameter, $S_{0}$. It includes the two wave cases from the current study as well as data from Lo et al. (2013), which includes measurements from of run-up of two successive 

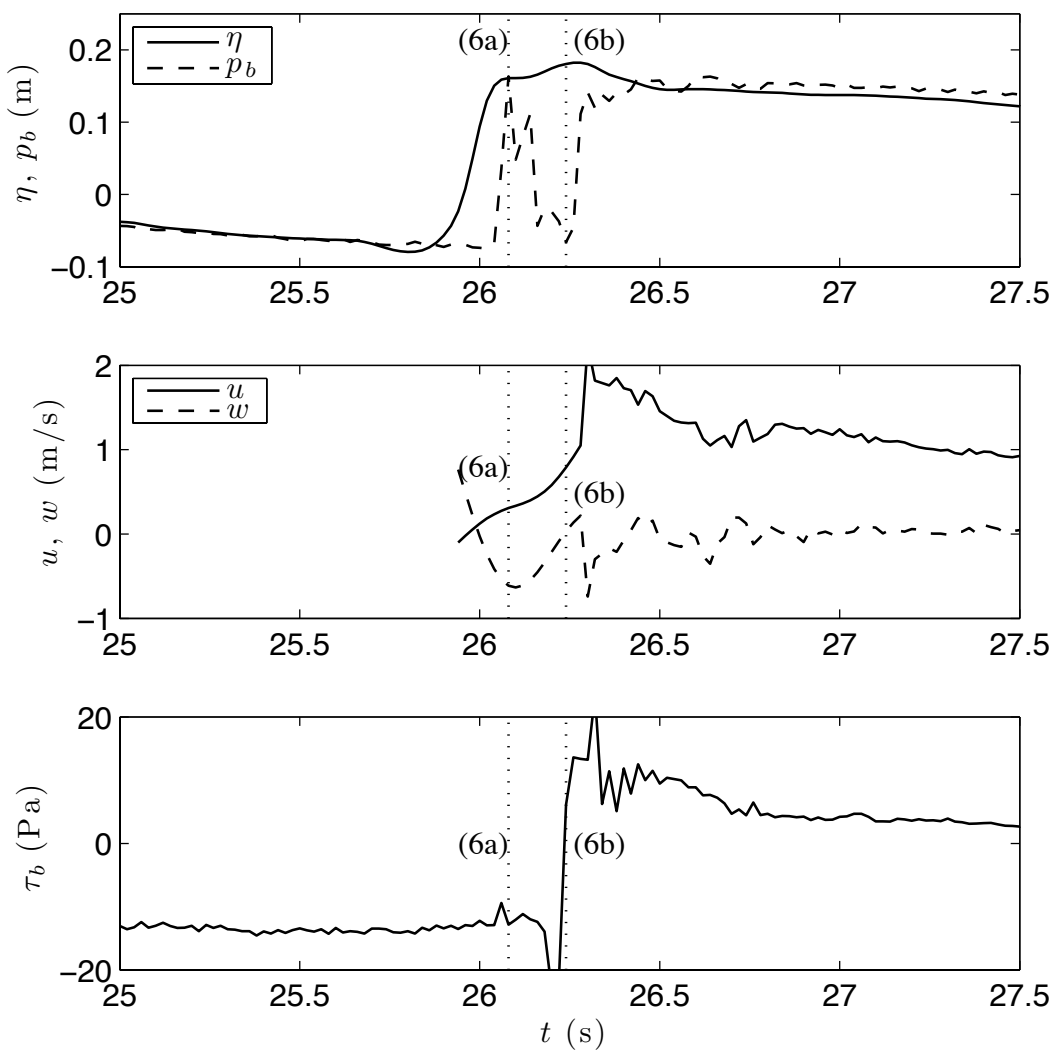

Figure 16: Data at the nearshore location $(h=0.10 \mathrm{~m})$ for SW1. Top panel: Free-surface displacement, $\eta$, and bed pressure, $p_{b}$; Middle panel: Near-bed velocity, $u, w$; Bottom panel: Bed shear stress, $\tau_{b}$.
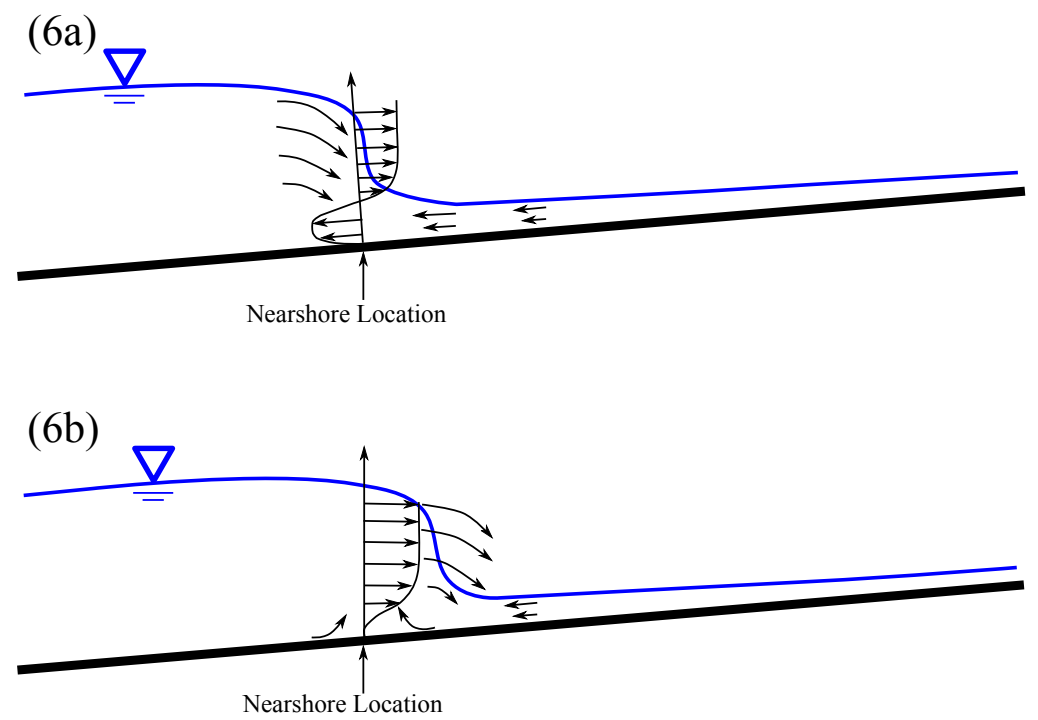

Figure 17: Sketch of flow patters and velocity profile corresponding to points (6a) and (6b) in Figure 16. 


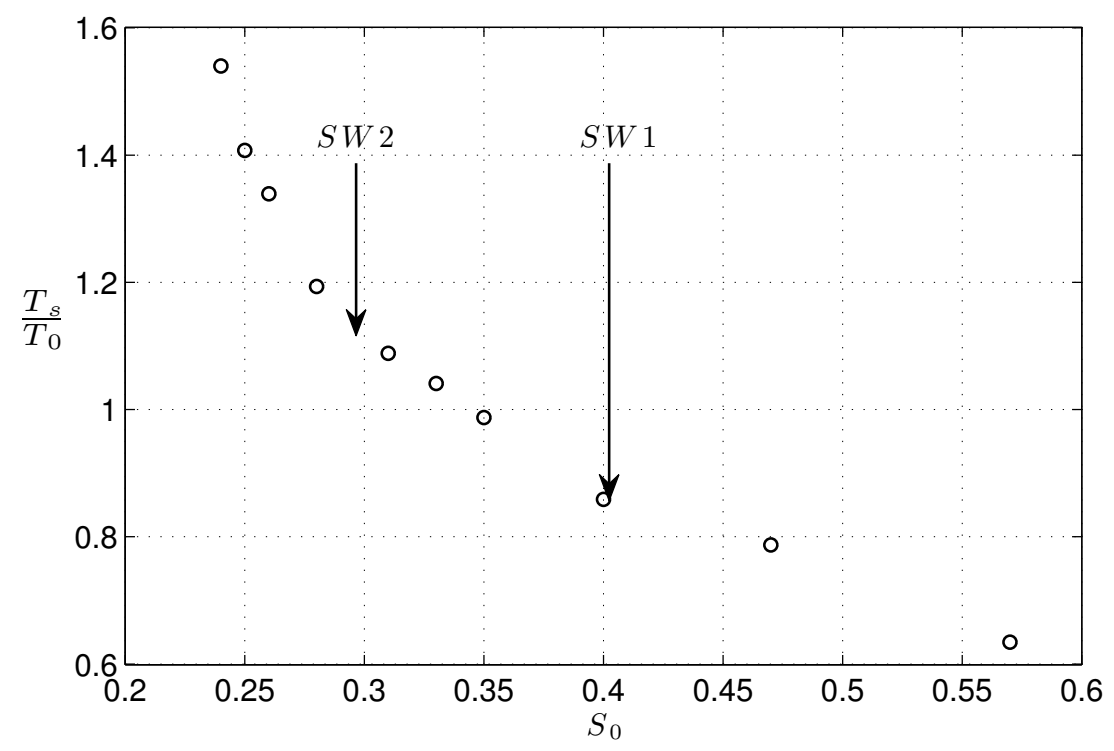

Figure 18: The swash period of a single solitary wave, $T_{s}$, normalized by effective wave period of incident wave, $T_{0}$, as a function of the slope parameter (adapted from PLY15). The arrows show the values of $S_{0}$ for the wave cases in the current study.

solitary waves with wave crests separated by approximately one wavelength on slopes of $s=1 / 20$, $s=1 / 10$ (small-scale laboratory facilities) and $s=1 / 12$ (same large-scale facility as the current study). The overall description of the interaction between two successive solitary waves on a plane beach can be distributed into three different zones in terms of the solitary wave slope parameter, $S_{0}$ : weakly interacting swash events [WI; $S_{0}>0.37 ; T_{s} / T_{0}<1$ ], where the swash event of the first wave is almost complete and the water depth is zero in the majority of the swash zone; strongly interacting swash events [SI(D); $\left.0.25<S_{0}<0.37 ; 1<T_{s} / T_{0}<1.2\right]$, where the majority of the swash of the first wave is in downrush; strongly interacting swash events [SI(U); $S_{0}<0.25$; $T_{s} / T_{0}>1.2$, where the majority of the swash of the first wave is in uprush. SW1 is an example of a WI event, whereas SW2 is an example of a SI(D) event. WI events are most likely when there is a 'weak wave-downrush interaction', whereas SI(D) events are most likely when there is a 'strong wave-downrush interaction'. SI(U) events are similar to 'wave capture' (Hughes and Moseley, 2007; Cáceres and Alsina, 2012), but the swash tip of the second wave does not necessarily overtake the swash tip of the first wave. The boundaries between the zones are defined here somewhat arbitrarily since in reality, there is a gradual transition between the three types of interactions, but the run-up data in Figure 19, $R_{B} / R_{A}$, support the description of the three zones. This characterization is limited to the interaction of only two successive solitary waves and the interaction of a third solitary wave with the swash of the first two might be different, particularly in strongly interacting swash events since the flow conditions under which the third wave climbs the slope will be different to those under which the second wave climbs the slope. Here, we conjecture that for weakly interacting swash events, it is likely that the third and subsequent waves would continue to only weakly interact with the previous and following waves. Thus, for weakly interaction waves, the period of shoreline oscillations would remain roughly constant, whereas for strongly interacting waves, the shoreline oscillations will not be periodic but will likely contain a range of timescales, as previously noted by Watson et al. (1994), Baldock and Holmes (1999) and others. 


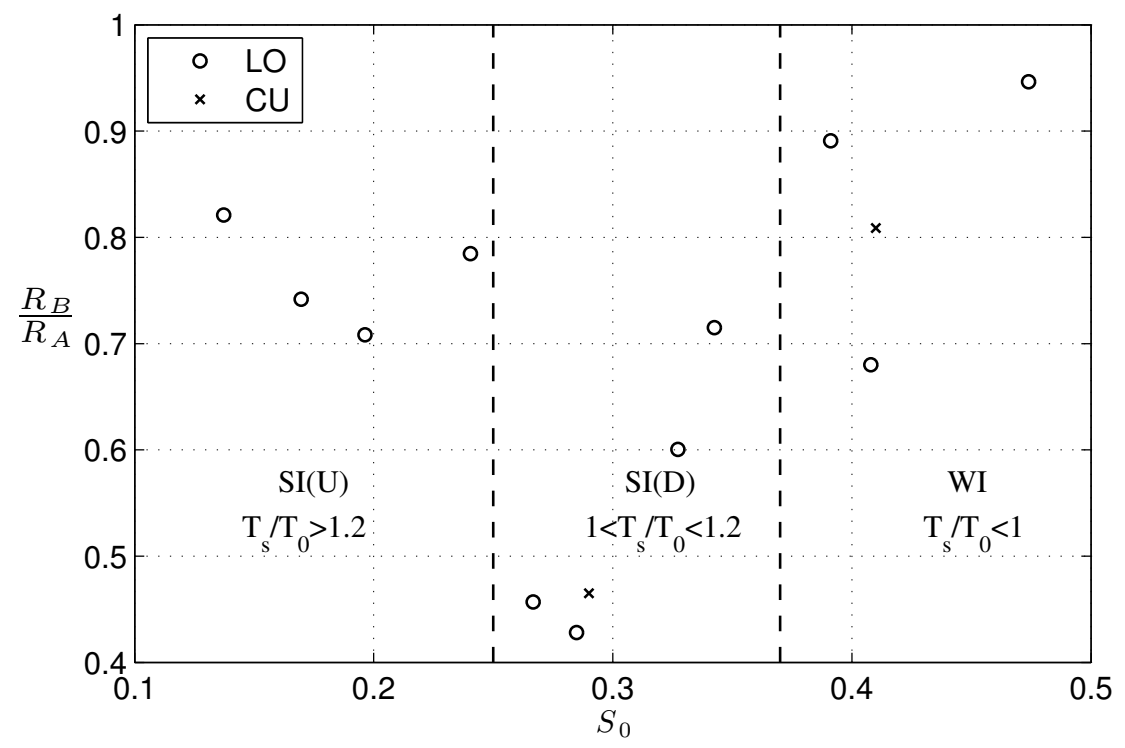

Figure 19: Run-up of second wave normalized by run-up of first wave for two successive solitary waves with wave crests separated by $0.9<T_{\text {sep }} / T_{0}<1.1$. LO: Lo et al. (2013); $C U$ : current data. Dashed vertical lines demarcate different zones: Weakly interacting, WI, $S_{0}>0.37$; Strongly interacting with the majority of the swash in downrush, SI(D), $0.25<S_{0}<0.37$; Strongly interacting with the majority of the swash in uprush, SI(U), $S_{0}<0.25$.

\section{Conclusions}

We have shown how the swash of successive solitary waves can be used to study the interaction of waves in the swash zone. Specifically, we have used two successive solitary waves that are separated in the constant depth region by approximately one wavelength of a single solitary wave and studied their interact on a plane sloping beach. The overall description of the interaction is linked to the ratio of the period of the swash to the period of the incoming waves, $T_{s} / T_{0}$, and in turn to the breaker type of the first wave. $T_{s} / T_{0}$ has been identified as an important parameter in the swash zone (Watson et al., 1994; Baldock and Holmes, 1999; Holland and Puleo, 2001; Masselink and Puleo, 2006; Hughes and Moseley, 2007; Brocchini and Baldock, 2008, and others), but we have shown results for isolated swash-swash interaction for different regimes of $T_{s} / T_{0}$ using successive solitary waves. Doing so has allowed us to propose a link between the swash period, incident wave period and the breaker type.

When the broken bore of the second wave overcomes the downrush of the first wave, there is a flow separation point at the bed with the near-bed flow changing direction from moving offshore to onshore in a bursting manner. In such a flow separation point, our measurements of bed shear stress, bed pressure and near-bed velocity show that the offshore-directed velocity persists close to the bed even as the velocity further away from the bed becomes onshore-directed. Thus there exists a shear layer in the velocity profile. Soon after, the bed shear stress changes sign and the velocity throughout the water column becomes onshore-directed. The bed pressure experiences a sudden decrease during the change of sign of bed shear stress that is associated with upwarddirected vertical fluid accelerations. This process provides evidence for a mechanism by which the sediment mobilized in a sheet flow regime during downrush is transported into the bore of the following wave and advected into the swash zone. Further experimental investigations of this mechanism over a porous bed would be useful to understand the likelyhood of fluidization of the 
bed.

\section{Acknowledgements}

The authors gratefully acknowledge the support of the National Science Foundation (CMMI1041541). The help of Yong Sung Park during the initial design stages of the shear plate sensor, and the help Paul Charles, Tim Brock, Jack Powers and Cameron Wilkins at Cornell University with the construction of the shear plate sensor is also acknowledged. The authors would also

like to thank Melora Park, Tim Maddux, Jason Killian and Adam Ryan at the Hinsdale Wave Research Laboratory at Oregon State University for their vital help with experimental setup and data acquisition. 


\section{References}

Alsina, J. M., CÁceres, I., Brocchini, M., And Baldock, T. E. 2012. An experimental study on sediment transport and bed evolution under different swash zone morphological conditions. Coastal Engineering 68:31-43.

Alsina, J. M., Falchetti, S., And Baldock, T. E. 2009. Measurements and modelling of the advection of suspended sediment in the swash zone by solitary waves. Coastal Engineering 56:621-631.

Bakhtyar, R., Barry, D. A., Li, L., Jeng, D. S., and Yeganeh-Bakhtiary, A. 2009. Modeling sediment transport in the swash zone: A review. Ocean Engineering 36:767-783.

Baldock, T. E. And Holmes, P. 1999. Simulation and prediction of swash oscillations on a steep beach. Coastal Engineering 36:219-242.

Baldock, T. E. And Hughes, M. G. 2006. Field observations of instantaneous water slopes and horizontal pressure gradients in the swash-zone. Continental Shelf Research 26:574-588.

Baldock, T. E., Kudo, A., Guard, P. A., Alsina, J. M., And Barnes, M. P. 2008. Lagrangian measurements and modelling of fluid advection in the inner surf and swash zones. Coastal Engineering 55:791-799.

Barnes, M. P., O’Donoghue, T., Alsina, J. M., And Baldock, T. E. 2009. Direct bed shear stress measurements in bore-driven swash. Coastal Engineering 56:853-867.

Boussinesq, J. 1872. Théorie des ondes et des remous qui se propagent le long d'un canal rectangulaire horizontal, en communiquant au liquide contenu dans ce canal des vitesses sensiblement pareilles de la surface au fond. J. Math. Pures Appl 2:55-102.

Brocchini, M. AND BALDoCK, T. E. 2008. Recent advances in modeling swash zone dynamics: Influence of surf-swash interaction on nearshore hydrodynamics and morphodynamics. Reviews of Geophysics 46:RG3003.

Cáceres, I. And Alsina, J. M. 2012. A detailed, event-by-event analysis of suspended sediment concentration in the swash zone. Continental Shelf Research 41:61-76.

Cowen, E. A., Sou, I. M., Liu, P. L.-F., And Raubenheimer, B. 2003. Particle image velocimetry measurements within a laboratory-generated swash zone. Journal of Engineering Mechanics 129:1119-1129.

El, G. A., Grimshaw, R. H. J., And Tiong, W. K. 2012. Transformation of a shoaling undular bore. Journal of Fluid Mechanics 709:371-395.

Elfrink, B. And BAldock, T. E. 2002. Hydrodynamics and sediment transport in the swash zone: a review and perspectives. Coastal Engineering 45:149-167.

Erikson, L., LARson, M., And Hanson, H. 2005. Prediction of swash motion and run-up including the effects of swash interaction. Coastal Engineering 52:285-302.

Galvin, C. 1990. Transformation of swell over a reef: Solitons. Shore \& Beach 58:31. 
Goring, D. G. 1978. Tsunamis-the propagation of long waves onto a shelf. PhD thesis, California Institute of Technology.

Grilli, S. T., Svendsen, I. A., And Subramanya, R. 1997. Breaking criterion and characteristics for solitary waves on slopes. Journal of waterway, port, coastal, and ocean engineering 123:102-112.

Holland, K. T. And Puleo, J. A. 2001. Variable swash motions associated with foreshore profile change. Journal of Geophysical Research 106:C3-4613-4623.

Hughes, M. G. And Moseley, A. S. 2007. Hydrokinematic regions within the swash zone. Continental Shelf Research 27:2000-2013.

Jackson, N. L., Masselink, G., And Nordstrom, K. F. 2004. The role of bore collapse and local shear stresses on the spatial distribution of sediment load in the uprush of an intermediatestate beach. Marine Geology 203:109-118.

Jensen, A., Pedersen, G. K., And Wood, D. J. 2003. An experimental study of wave run-up at a steep beach. Journal of Fluid Mechanics 486:161-188.

Kikkert, G. A., O’Donoghue, T., Pokrajac, D., And Dodd, N. 2012. Experimental study of bore-driven swash hydrodynamics on impermeable rough slopes. Coastal Engineering 60:149-166.

Kikkert, G. A., Pokrajac, D., O’Donoghue, T., And Steenhauer, K. 2013. Experimental study of bore-driven swash hydrodynamics on permeable rough slopes. Coastal Engineering $79: 42-56$.

Kobayashi, N. And LaWrence, A. R. 2004. Cross-shore sediment transport under breaking solitary waves. Journal of Geophysical Research 109:C03047.

Li, Y. AND RAichlen, F. 2002. Non-breaking and breaking solitary wave run-up. Journal of Fluid Mechanics 456:295-318.

Lo, H. Y., PARK, Y. S., And LiU, P. 2013. On the run-up and back-wash processes of single and double solitary waves-An experimental study. Coastal Engineering 80:1-14.

Longo, S., Petti, M., And Losada, I. J. 2002. Turbulence in the swash and surf zones: a review. Coastal Engineering 45:129-147.

Madsen, P. A., Fuhrman, D. R., And Schäffer, H. A. 2008. On the solitary wave paradigm for tsunamis. Journal of Geophysical Research 113:C12012.

Masselink, G. And Puleo, J. A. 2006. Swash-zone morphodynamics. Continental Shelf Research 26:661-680.

Meyer, R. E. And TAYlor, A. D. 1972. Waves on beaches and resulting sediment transport, chapter Run-up on beaches. Academic Press New York.

O’Donoghue, T., Pokrajac, D., And Hondebrink, L. J. 2010. Laboratory and numerical study of dambreak-generated swash on impermeable slopes. Coastal Engineering 57:513-530. 
Othman, I. K., Baldock, T. E., And Callaghan, D. P. 2014. Measurement and modelling of the influence of grain size and pressure gradient on swash uprush sediment transport. Coastal Engineering 83:1-14.

Pedersen, G. K., Lindstroİžm, E., Bertelsen, A. F., Jensen, A., Laskovski, D., And SæleviK, G. 2013. Runup and boundary layers on sloping beaches. Physics of Fluids 25:012102.

Peregrine, D. H. 1966. Calculations of the development of an undular bore. Journal of Fluid Mechanics 25:321-330.

Peregrine, D. H. 1983. Breaking waves on beaches. Annual review of fluid mechanics 15:149178.

Peregrine, D. H. And Williams, S. M. 2001. Swash overtopping a truncated plane beach. Journal of Fluid Mechanics 440:391-399.

Postacchini, M., Othman, I. K., Brocchini, M., And Baldock, T. E. 2014. Sediment transport and morphodynamics generated by a dam-break swash uprush: Coupled vs uncoupled modeling. Coastal Engineering 89:99-105.

Pritchard, D. 2009. Sediment transport under a swash event: the effect of boundary conditions. Coastal Engineering 56:970-981.

Pujara, N. And LiU, P. L.-F. 2014. Direct measurements of local bed shear stress in the presence of pressure gradients. Experiments in fluids 55:1767.

Pujara, N., LiU, P. L.-F., And YeH, H. 2015. The swash of solitary waves: flow evolution, bed shear stress and run-up. Journal of Fluid Mechanics (accepted).

Puleo, J. A. And Butt, T. 2006. The first international workshop on swash-zone processes. Continental Shelf Research 26:556-560.

Shen, M. C. And Meyer, R. E. 1963. Climb of a bore on a beach. Part 3. Run-up. Journal of Fluid Mechanics 16:113-125.

Sou, I. M., Cowen, E. A., And LiU, P. L.-F. 2010. Evolution of the turbulence structure in the surf and swash zones. Journal of Fluid Mechanics 644:193-216.

SOU, I. M. AND YEH, H. 2011. Laboratory study of the cross-shore flow structure in the surf and swash zones. Journal of Geophysical Research 116:C03002.

Sumer, B. M., Sen, M. B., Karagali, I., Ceren, B., Fredsøe, J., Sottile, M., Zilioli, L., And Fuhrman, D. R. 2011. Flow and sediment transport induced by a plunging solitary wave. Journal of Geophysical Research 116:C01008.

Synolakis, C. E. And Bernard, E. N. 2006. Tsunami science before and beyond Boxing Day 2004. Philosophical Transactions of the Royal Society A: Mathematical, Physical and Engineering Sciences 364:2231-2265.

Ting, F. C. K. 2006. Large-scale turbulence under a solitary wave. Coastal Engineering 53:441462. 
Ting, F. C. K. 2008. Large-scale turbulence under a solitary wave: Part 2. Coastal Engineering $55: 522-536$.

Watson, G., Barnes, T. C. D., And Peregrine, D. H. 1994. The generation of low-frequency waves by a single wave group incident on a beach. Coastal Engineering Proceedings 1:1-26.

Wiegel, R. L. 1990. Transformation of swell over a reef. Shore $\mathscr{E}$ Beach 58:31.

Yeh, H. H., Ghazali, A., And Marton, I. 1989. Experimental study of bore run-up. Journal of Fluid Mechanics 206:563-578.

YeH, H. H. And Mok, K. M. 1990. On turbulence in bores. Physics of Fluids A: Fluid Dynamics $2: 821-828$. 